\title{
VARIAÇÕES ESPACIAIS NA CONDUTIVIDADE HIDRÁULICA DO SOLO EM ÁREA DE RECARGA DO SISTEMA AQUÍFERO GUARANI
}

Rodrigo Esteves ROCHA

Didier GASTMANS

Marcelo Donadelli SACCHI

Marcelo Dias de OLIVEIRA

\begin{abstract}
RESUMO
A condutividade hidráulica de solos constitui informação importante para a compreensão dos processos de infiltração de água, reduzindo incertezas nas estimativas de balanços hídricos em bacias hidrográficas. Além de possibilitar a compreensão da distribuição espacial da recarga em aquíferos livres, auxilia também na elaboração de estratégias de uso racional e integrado de águas superficiais e subterrâneas. Nesse sentido, o trabalho teve como objetivo geral determinar a variabilidade espacial da condutividade hidráulica em uma bacia hidrográfica localizada na sub-bacia do Alto Jacaré-Pepira, importante zona de recarga do Sistema Aquífero Guarani (SAG), comparando as variações observadas com aspectos fisiográficos e geológicos. A condutividade hidráulica foi medida em campo utilizando-se um Permeâmetro de Guelph, que possibilita a medição da recarga com carga constante, responsável pela manutenção da carga hidráulica em um furo artificial no solo. A condutividade hidráulica dos solos na área variou de $1,99 \mathrm{E}-6$ até $6,02 \mathrm{E}-2 \mathrm{~cm} \mathrm{~s}^{-1}$, sendo os maiores valores associados a solos arenosos derivados de arenitos das formações Botucatu e Pirambóia, enquanto os menores a solos argilosos, provenientes da alteração de rochas basálticas da Formação Serra Geral. A distribuição espacial da condutividade hidráulica na área da microbacia permitiu verificar a forte correlação entre a condutividade hidráulica e o tipo litológico aflorante, a partir da comparação visual com o mapa geológico da área. A variabilidade da condutividade é correlacionada aos solos na área, e ambos são essencialmente controlados pelas litologias aflorantes e por sua posição no relevo.
\end{abstract}

Palavras-chave: Permeâmetro de Guelph; Recarga; Sistema Aquífero Guarani; Microbacia hidrográfica.

\section{ABSTRACT}

SPATIAL VARIATIONS IN SOIL HYDRAULIC CONDUCTIVITY IN A GUARANI AQUIFER SYSTEM RECHARGE AREA. Data on the hydraulic conductivity of soils are important for the understanding of water infiltration processes, and contribute to reduce uncertainties in water balance estimation in watersheds. These data not only allow a better understanding of the spatial distribution of recharge rates in unconfined aquifers, but also are used to develop strategies for the rational and integrated use of surface water and groundwater. In this regard, the objective of this study was to determine the spatial variability of the hydraulic conductivity in a watershed and compare the observed variations with physiographic and geological aspects. The study area is located in the upper portion of the Jacaré-Pepira sub-basin, an important recharge area of the Guarani Aquifer System (GAS). The hydraulic conductivity was measured using a Guelph Permeameter, which allows the measurement of the recharge under constant hydraulic head, responsible for maintaining the hydraulic head in a 
borehole in the ground. The hydraulic conductivity of soils in the study area varied from $1.99 \mathrm{E}-6$ to $6.02 \mathrm{E}-2 \mathrm{~cm} \mathrm{~s}^{-1}$, with the highest values associated with sandy soils derived from sandstones of the Botucatu and Piramboia formations, and the lowest ones associated with clayey soils formed by weathering of basaltic rocks from the Serra Geral Formation. A map of hydraulic conductivity distribution of the watershed was created with data measured in the study area. Visual comparison between this map and the geological map of the area corroborated the strong correlation between the hydraulic conductivity and the lithology. Therefore, the variability of the hydraulic conductivity is essentially controlled by outcropping lithologies and their position in the relief.

Keywords: Guelph permeameter; Recharge; Guarani Aquifer System; Small watershed.

\section{INTRODUÇÃO}

Eventos de escassez ou excesso de água alternam-se com frequência e intensidade anômalas em relação ao esperado da variabilidade interanual dos climas (MARENGO 2008). Como a atividade antrópica altera e é alterada pela presença de água, a disponibilidade de recursos hídricos é alvo de discussões na mídia e população em geral (DA SILVA 1998). A gestão pública desse importante recurso natural é responsável por aspectos como a limitação do volume de captação e da impermeabilização em áreas de recarga de aquíferos (CAMPOS 2004). O conhecimento científico é a chave para a tomada de atitudes que visem o aproveitamento sustentável da água.

A qualidade, quantidade e disponibilidade da água são os principais termos explicitados por pesquisas hidrológicas (CORDEIRO NETTO \& TUCCI 2003). Essas propriedades são a consequência das condições de ocorrência a que estão submetidas as fases do ciclo hidrológico em um determinado espaço (TUCCI 2007). Entender os mecanismos hidrológicos em áreas de recarga dos aquíferos é de fundamental importância para o gerenciamento de recursos hídricos. A gestão integrada dos recursos hídricos necessita de informações que permitam a quantificação de volumes explotáveis de água, para tanto, a quantificação confiável das taxas de recarga faz-se indispensável.

A água do solo é o elo entre a precipitação e os aquíferos livres; portanto, entender os mecanismos de seu movimento é de grande importância para a compreensão dessa recarga (CHENG et al. 2014). A renovação das águas subterrâneas ocorre a partir da precipitação como recarga direta através da zona não saturada. Nesse sentido, estimativas confiáveis de condutividade hidráulica são pré-requisito para precisão das estimativas de fluxo de água e transporte de solutos através do perfil do solo.

Do ponto de vista conceitual, a condutividade hidráulica é um coeficiente de proporcionalidade que descreve a facilidade com que a água percorre um meio poroso (FETTER 2000). Essa propriedade foi primeiro calculada por DARCY (1856), que buscava compreender o fenômeno de percolação da água em um meio poroso. Para isto construiu um aparato que mantinha uma coluna de areia saturada com água, podendo controlar a carga hidráulica de entrada e medir o volume de água que saia. A partir de seus experimentos concluiu que a vazão é diretamente proporcional à diferença da carga d'água entre os limites da coluna e à área da seção transversal dela, e inversamente proporcional ao seu comprimento.

Por meio destas relações foi obtida empiricamente a primeira equação para quantificar o fluxo de água em meio poroso e saturado. Para meios não saturados a primeira equação foi proposta por BUCKINGHAM (1907) com base nas semelhanças com a teoria dos fluxos de calor e elétrico. $\mathrm{O}$ avanço da equação teórica de Darcy-Buckingham foi a possibilidade de relacionar o conteúdo de água em solo não saturado com a condutividade hidráulica. A equação apenas se tornou prática por meio da sua combinação, por RICHARDS (1931), com a equação da continuidade da mecânica de fluidos, e da proposição de um método de aplicação pelo mesmo autor.

Muitas pesquisas foram desenvolvidas com o objetivo de refinar os parâmetros da equação de Richards e desenvolver métodos de determinação da condutividade hidráulica em campo e em laboratório (BACCHI et al. 1991). Dentre os parâmetros estudados em literatura, um dos mais relevantes é o conjunto de diferenças do comportamento da condutividade hidráulica em meios sa- 
turados e não saturados. Quando saturado, o solo atinge seu valor de condutividade máxima, pois todos os poros estão preenchidos pelo fluido analisado. Quando não saturado, a presença de ar em alguns poros reduz a velocidade de fluxo, portanto reduzindo rapidamente a condutividade hidráulica (HILLEL 1971).

Segundo GONÇALVES \& LIBARDI (2013), a condutividade saturada do solo é definida, principalmente, pela estrutura e não pela textura do solo. Os componentes da estrutura do solo que agem sobre essa propriedade são a forma e continuidade dos poros, assim como a presença de poros com mais de $50 \mathrm{~mm}$, denominados macroporos, e sua orientação. Já em solos não saturados, a relação entre o conteúdo de água no solo e a condutividade é diretamente proporcional (LIBARDI \& MELO FILHO 2006). O conteúdo de água é um parâmetro que pode ser medido, e uma pequena alteração de 1 a $2 \%$ em seu valor pode variar em até $170 \%$ a condutividade do solo (FALLEIROS et al. 1998).

Para contabilizar este fenômeno, modelos matemáticos complexos foram desenvolvidos de modo a considerar como variável o teor de água no meio (VAN GENUCHTEN 1980).

Os modelos matemáticos desenvolvidos para os métodos de determinação da condutividade não saturada em campo exigem o conhecimento também da condutividade saturada (ZHANG \& SCHAAP 2019). Modelos mais antigos seguiam o procedimento proposto por HILLEL (1971), em que se admitia que o gradiente de potencial total é unitário, pois sua estimativa é muito difícil em campo. No entanto, GONÇALVES \& LIBARDI (2013) desenvolveram o cálculo sem considerar o gradiente de potencial total como unitário. Eles utilizaram artifícios matemáticos para propor um novo modelo, cujos parâmetros básicos são o conteúdo de água em volume $(\theta)$, o tempo de redistribuição $(t)$, e a profundidade do solo $(L)$.

Outro fator importante na determinação da condutividade do solo é a distribuição do fluxo d'água nas direções horizontal e vertical (FREEZE \& CHERRY 1979). Para os métodos de condutividade saturada, é considerado que o bulbo de saturação se forma tanto no sentido vertical quanto no horizontal (MESQUITA \& MORAES 2004). Já para os métodos de condutividade não saturada, como o método do perfil instantâneo proposto por WATSON (1966), o fluxo calculado é apenas o vertical. Isto implica em um desvio dos valores de condutividade desejados caso exista fluxo na direção horizontal. Fatores que podem gerar um fluxo horizontal significativo são a presença de horizontes pedológicos com contraste de permeabilidade e a proximidade com o nível d'água.

Devido aos processos de gênese, os solos naturalmente apresentam variações horizontais e verticais de naturezas física, como a porosidade e a permeabilidade, e química, como a mineralogia. Elas são marcadas pelos horizontes pedológicos, que implicam em uma variabilidade da condutividade hidráulica no sentido vertical (FIORI et al. 2010). Diferenças no material de origem ou da vegetação de cobertura contribuem para essa variabilidade mesmo em solos com textura semelhante, ou quando pequenas distâncias são consideradas (KUTILEK \& NIELSEN 1994). Também deve ser considerada a variação causada pelo uso e ocupação do solo, pois solos manejados podem apresentar significativas alterações no valor da condutividade (SILVA \& KATO 1997).

A condutividade hidráulica saturada não pode ser prevista para as diferentes classes de solo somente a partir da textura, porque também são importantes os efeitos concorrentes da mineralogia, estrutura e porosidade (MESQUITA \& MORAES 2004). A condutividade hidráulica é, portanto, uma propriedade básica do solo, e faz parte do conjunto de processos que definem o fluxo em sub-superfície (SOTO \& VILAR 1999). Entretanto, numa bacia, as propriedades do solo que afetam a condutividade hidráulica são altamente variáveis espacialmente.

Para entender a variação espacial de um fenômeno, deve-se levar em consideração a possibilidade de o valor de cada ponto no espaço estar relacionado, de algum modo, com valores obtidos de pontos situados a certa distância, sendo razoável supor que a influência é tanto maior quanto menor for a distância entre os pontos (YAMAMOTO \& LANDIM 2013). É o que acontece com a condutividade hidráulica, onde medidas feitas em locais próximos variam menos do que as feitas à maiores distâncias. Por esse motivo, a descrição da variação espacial de propriedades do solo é frequentemente feita usando a teoria estatística das variáveis regionais, ou simplesmente geoestatística (KUTILEK \& NIELSEN 1994).

A área em que foram realizados os levantamentos de campo está situada em bacia hidrográfica sobre área de afloramento do Sistema Aquífero Guarani (SAG). Este representa um importante aquífero transfronteiriço, localizado na região ocidental do continente Sul-Americano, abrangendo uma área total de $1.087 .879,5 \mathrm{~km}^{2}$, re- 
presentando fonte de água potável para mais de 90 milhões de pessoas (OEA 2009, GASTMANS et al. 2010). Em função da sua importância como fonte de água potável torna-se premente o conhecimento a respeito das características hidrogeológicas de suas áreas de recarga, uma vez que a resiliência do recurso está associada à sua taxa de renovação.

A área está localizada em uma Área de Proteção Ambiental (APA), na qual os recursos hídricos representam uma importante atração turística, especialmente para a cidade de Brotas. Está inserida na bacia hidrográfica do rio Jacaré-Pepira, um dos principais rios da UGRHI-13 (Unidade de Gerenciamento de Recursos Hídricos). A bacia estudada está situada sobre área de recarga do Sistema Aquífero Guarani (SAG), por isso é um campo de pesquisa para estudos visando compreender a recarga subterrânea e interação entre águas superficiais e subterrâneas (BATISTA \& GASTMANS 2015, BATISTA et al. 2018). No entanto, nenhum estudo apresentou a quantificação da condutividade hidráulica do solo e sua variação espacial em função das variações litológicas existentes nas áreas de afloramento do SAG.

Nesse sentido, o objetivo desse trabalho foi o de determinar a variabilidade espacial da condutividade hidráulica em uma microbacia localizada na bacia do Alto Jacaré-Pepira (SP), comparando os resultados com aspectos fisiográficos e geológicos presentes na área.

\section{CARACTERIZAÇÃO DA ÁREA DE ESTUDO}

A área de estudo constitui uma pequena bacia hidrográfica, com área aproximada de $41 \mathrm{~km}^{2}$. Está situada na sub-bacia do Alto Jacaré-Pepira, em sua margem esquerda, próximo à divisa dos municípios paulistas de Brotas e Dois Córregos (Figura 1).
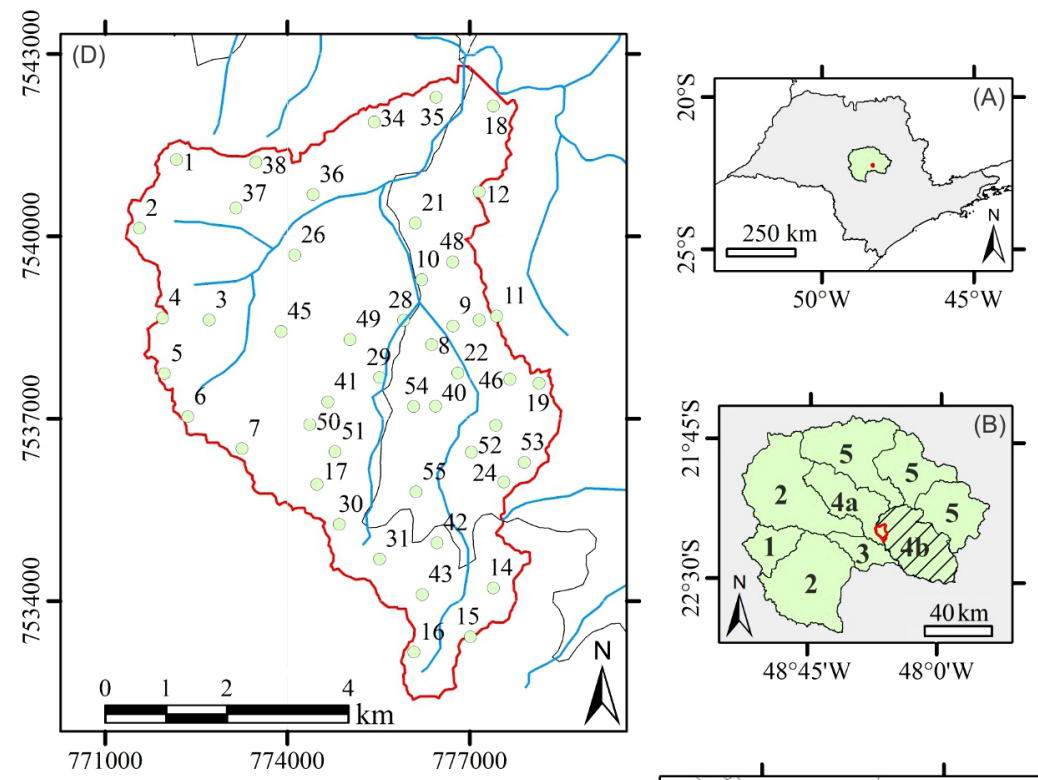

\section{Legenda}
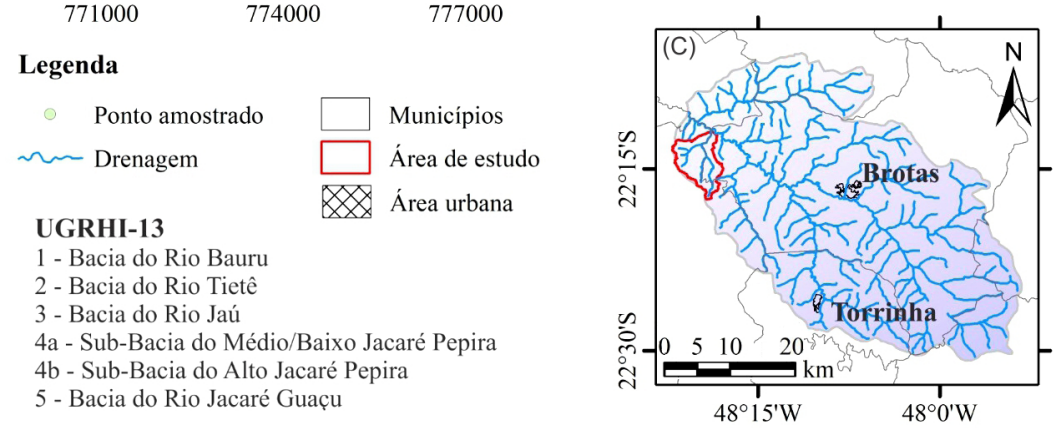

FIGURA 1 - Localização da UGRHI-13 no estado de São Paulo (A), da sub-bacia do Alto Jacaré-Pepira na UGRHI-13 (B), da área de estudo na sub-bacia do Alto Jacaré-Pepira (C) e dos pontos em que foram determinadas as condutividades hidráulicas saturadas com o permeâmetro de Guelph (D). 
A sub-bacia hidrográfica do rio Jacaré-Pepira estende-se por uma área de $1.411,91 \mathrm{~km}^{2}$, ocupando $8,86 \%$ da área da bacia hidrográfica do rio Tietê-Jacaré (BH-TJ) - UGRHI-13, abrangendo os municípios paulistas de São Pedro, Torrinha, Brotas, Dourado, Dois Córregos, Ribeirão Bonito e Itirapina. A nascente principal do rio que dá nome a sub-bacia está localizada na Serra de Itaqueri, inserida na Província da Depressão Periférica, Zona do Médio-Tietê (ALMEIDA 1964), próxima à divisa dos municípios São Pedro/Itirapina/Brotas, a uma altitude aproximada de $960 \mathrm{~m}$ no reverso do relevo de cuestas basálticas, onde são reconhecidos setores elevados de planalto, com níveis rebaixados por erosão e controlados estruturalmente (BUENO \& MENDES 1999).

O rio Jacaré-Pepira deságua no rio Tietê, no município de Ibitinga, situado a aproximadamente $400 \mathrm{~m}$ acima do nível médio do mar, apresentando, portanto, ao longo do seu curso um desnível de quase $500 \mathrm{~m}$.

A sub-bacia do Alto Jacaré Pepira apresenta, como características gerais, altas demandas de

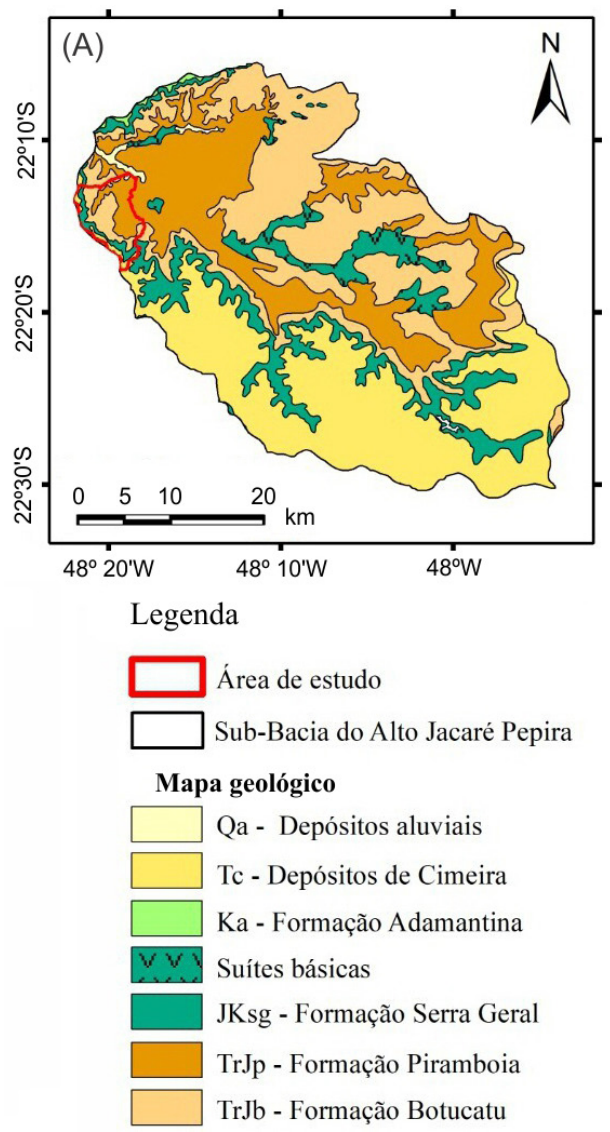

água para irrigação, média a alta susceptibilidade a erosão nas cabeceiras do Jacaré-Pepira e a inundações, principalmente nas áreas urbanas (CRH 2006). Entretanto, apresenta boa cobertura de vegetação natural remanescente, que ocupa cerca de $9 \%$ da área da UGRHI 13, sendo as categorias de maior ocorrência a Floresta Estacional Semidecidual e a Savana (SSRH/CRHi 2011).

Segundo a classificação de Köppen (PEEL et al. 2007), o clima que predomina na região é Cwa - subtropical úmido, caracterizado por verão quente e úmido e inverno seco (IPT 2015). Segundo BATISTA (2015), a precipitação média anual varia entre 1.100 e $1.400 \mathrm{~mm}$; os valores mínimos ocorrem no mês de julho $(30 \mathrm{~mm})$ e os máximos entre os meses de dezembro e janeiro $(250 \mathrm{~mm})$. No mês de julho ocorre a média de temperatura mais baixa $\left(16,4^{\circ} \mathrm{C}\right)$, enquanto a média mais alta ocorre no mês de fevereiro $\left(22,5^{\circ} \mathrm{C}\right)$. A temperatura média anual da área varia entre $22,5^{\circ} \mathrm{C}$ e $16,4{ }^{\circ} \mathrm{C}$, sendo o valor médio e desvio padrão de $20,02 \pm 2,31^{\circ} \mathrm{C}$.

$\mathrm{Na}$ área de estudo ocorrem seis grupos de solos, a saber (Figura 2): Argissolos Vermelho-Amarelos,
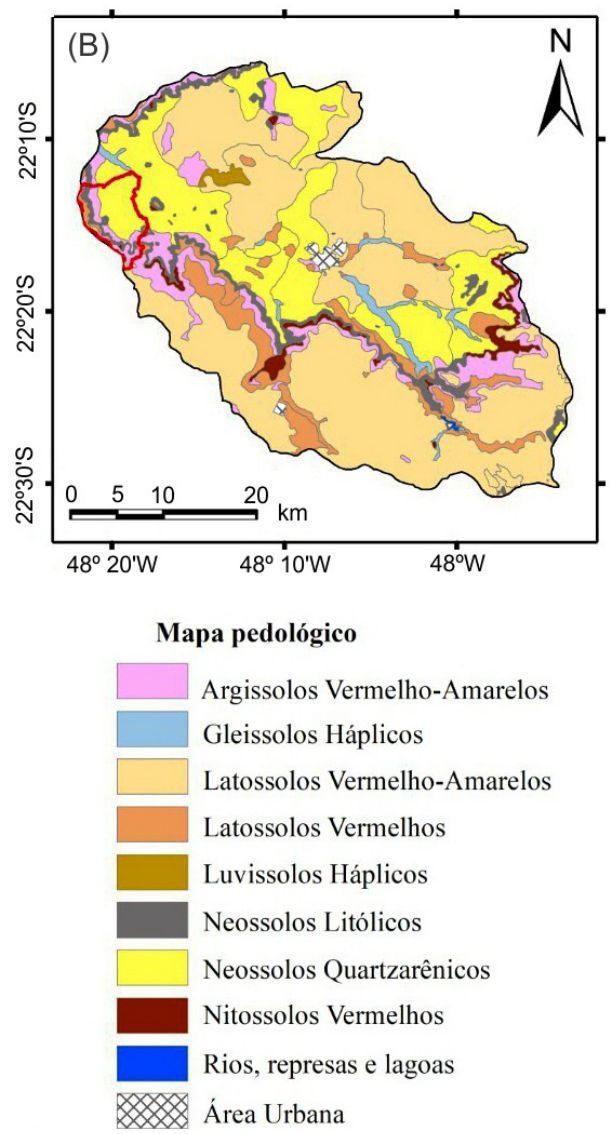

FIGURA 2 - Mapa geológico (A) e dos tipos de solo (B) da Bacia do Alto Jacaré Pepira, com destaque para a área de estudo (em vermelho) 
Gleissolos Háplicos, Latossolos Vermelho-Escuros textura média, Latossolos Vermelho-Amarelos textura média, Luvissolos Háplicos, Neossolos Quartzarênicos e Nitossolos Vermelhos (ROSSI 2017), associados as distintas unidades geológicas que constituem o arcabouço geológico da área.

Existe correlação entre o padrão da rede de drenagem e as unidades aquíferas presentes na área, indicando que as características geológicas e hidrológicas estão intimamente relacionadas. As unidades geológicas aflorantes são principalmente os sedimentos clásticos, predominantemente arenosos das formações Botucatu e Piramboia, e as rochas ígneas basálticas do Grupo São Bento, ambas do Mesozoico, as rochas sedimentares do Grupo Bauru, os sedimentos pertencentes à Formação Itaqueri e depósitos correlatos (Serra de São Carlos), de idade cretácea a cenozoica, e os sedimentos aluvionares quaternários associados à rede de drenagem (RABELO 2006) (Figura 2).

Os afloramentos das rochas sedimentares pertencentes às formações Piramboia e Botucatu, dominadas por fácies de arenitos, constituem importante zona de recarga do Sistema Aquífero Guarani (GESICKI 2007). Já nos basaltos e diabásios da Formação Serra Geral (Grupo São Bento) ocorrem sistemas de fraturas que permitem a ocorrência do Aquífero Serra Geral (MONTANHEIRO et al. 2016).

\section{MATERIAIS E MÉTODOS}

Para a seleção dos pontos de realização dos ensaios foi necessária a delimitação da área de estudo, que foi baseada na definição dos divisores de água. Para tanto, foram utilizados dados topográficos da base de dados da missão SRTM (Shuttle Radar Topography Mission) com definição de 30 $\mathrm{m}$, disponibilizados pelo USGS (United States Geological Survey) na plataforma Earth Explorer, disponíveis em: https:earthexplorer.usgs.gov/.

A delimitação dos divisores foi realizada com ferramentas do ArcToolBox no ArcGIS (ESRI 2011). Inicialmente, foi gerado um Modelo Digital de Terreno (MDT), a partir dos dados SRTM, e, em seguida, aplicadas ferramentas de análise espacial de hidrologia, como a ferramenta de definição de drenagens e escoamento. Por fim, foi obtida a delimitação da bacia hidrográfica, definida a partir da determinação do ponto exutório. O contorno da bacia é o limite geográfico da área, gerado como um arquivo em formato shapefile de linhas. O shapefile foi exportado para o software Google Earth e, a partir da análise das imagens, foram definidos os pontos para realização dos ensaios, em função de sua distribuição espacial e acesso (Figura 1).

A partir do MDT gerado, foi obtido o mapa de declividade da área, que envolve a determinação da inclinação do terreno em relação ao plano horizontal. Esse mapa foi construído com o software ArcGIS (ESRI 2011), utilizando ferramentas de análise espacial a partir do modelo digital de elevação (MDE). A informação dos valores de declividade pode ser apresentada em graus ou em porcentagem. É possível ainda definir classes para a divisão dos diferentes valores de inclinação ou classificar a variação segundo uma rampa de valores.

3.1 Determinação da condutividade hidráulica saturada do solo

A condutividade hidráulica é o parâmetro mais significativo para fenômenos relacionados ao fluxo e ao transporte de fluídos no solo, especialmente água e alguns contaminantes. No entanto, em função da variabilidade textural dos solos, a determinação espacial desse parâmetro é complexa e exige a realização de ensaios pontuais, e sua quantificação representa uma estimativa, cuja precisão depende tanto do método aplicado quanto da interpretação das informações coletadas (KRESIC 2007). Ao se aplicarem diferentes métodos na determinação da condutividade hidráulica, os resultados podem variar para diferentes condições de campo (MOHANTY et al. 1994).

Dentre os métodos mais empregados na determinação da condutividade hidráulica in situ na zona não saturada do solo, destaca-se o método do Permeâmetro de Guelph, especialmente por conta da extensa descrição na literatura clássica sobre seu funcionamento e aplicação para solos residuais (REYNOLDS \& ELRICK 1985, 1987; KANWAR et al. 1990). Segundo SALVERDA \& DANE (1993), o método de Guelph apresenta menos erros para solos de textura mais grossa, que é um fator positivo, pois a área de estudo é constituída por cerca de $70 \%$ de solos arenosos.

O método do permeâmetro Guelph foi desenvolvido por REYNOLDS et al. (1983) para a determinação in situ da condutividade hidráulica saturada de campo $\left(K_{f s}\right)$ e, posteriormente, estendida por REYNOLDS \& ELRICK (1985).

A determinação da condutividade hidráulica saturada é feita a partir da equação de RICHARDS 
(1931), para fluxo permanente em furo cilíndrico, representada abaixo:

$Q=\left[2 \pi H^{2} / C+\pi a^{2}\right] K_{f s}+[2 \pi H / C] \Phi_{G m}$

Onde: $Q\left[\mathrm{~L}^{3} \mathrm{~T}^{-1}\right]$ representa a vazão a carga constante, $H[\mathrm{~L}]$ a altura de água constante no furo de sondagem; $K_{f s}\left[\mathrm{LT}^{-1}\right]$ é a condutividade hidráulica saturada medida in situ, $a[\mathrm{~L}]$ é o raio do furo de sondagem, $\Phi_{G m}\left[\mathrm{~L}^{2} \mathrm{~T}^{-1}\right]$ é o potencial matricial de fluxo e $C$ [adimensional] um parâmetro denominado "fator de forma", que depende da relação $H / a$ e do tipo de solo.

O permeâmetro utilizado foi o modelo 2800K1 da SOILMOISTURE EQUIPMENT CORPORATION (2012b). Este equipamento foi escolhido por ser de fácil uso em campo e por ser portável. O esquema de montagem do equipamento, a execução do ensaio e as variáveis apresentadas na equação 1 , estão esquematizados na figura 3 .

Os procedimentos de campo envolveram o registro dos valores de referência para cada teste. Os dados coletados posteriormente foram utilizados para a estimativa da condutividade hidráulica saturada a partir de planilha Excel, disponibilizada da SOILMOISTURE EQUIPMENT CORPORATION (2012a). Os cálculos foram fei- tos com base no método de duas cargas, quando possível, no entanto, em alguns pontos foi necessário o uso da média entre duas cargas simples.

\subsection{Análise geoestatística}

Para efetuar estimativas de valores para superfícies não amostradas entre pontos de coleta de dados foram seguidas algumas premissas. A primeira é a análise estatística, que está presente na etapa de organização e avaliação dos dados coletados em campo. Essa é necessária, pois permite a identificação das características da população.

Os dados obtidos em campo foram organizados em uma planilha com o software Microsoft Excel $^{\circledR}$ e a Condutividade Hidráulica Saturada $\left(\mathrm{K}_{\mathrm{sat}}\right)$ foi tratada como uma variável quantitativa contínua para realizar a análise estatística descritiva, efetuada com o software PAST versão 3.20 (HAMMER et al. 2001).

$\mathrm{Na}$ análise estatística utilizou-se para a definição de valores anômalos (outliers) acima da faixa amostral a equação abaixo, segundo definição de NIST/SEMATECH (2003):

$$
\text { Outlier }=Q 3+1,5 \text { FIQ }
$$

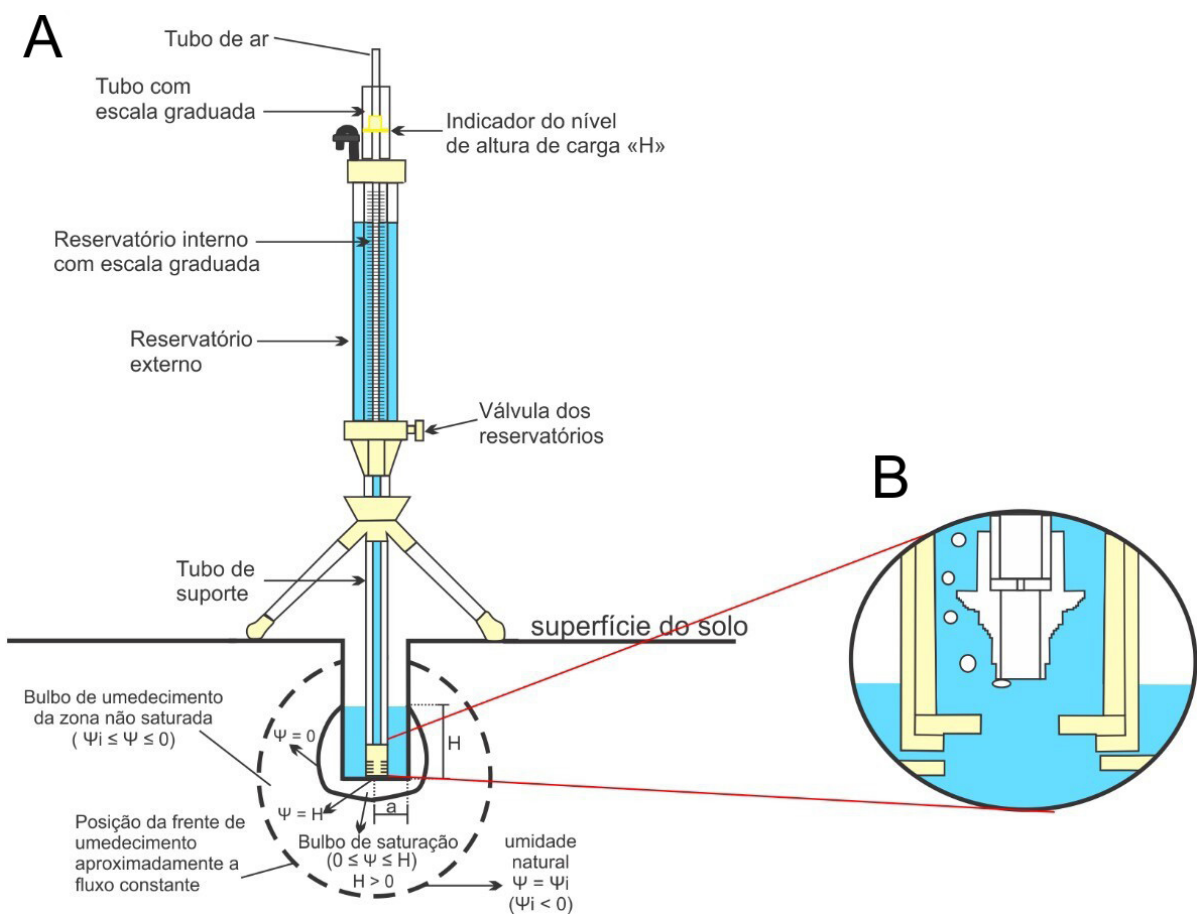

FIGURA 3 - Modelo esquemático do Permeâmetro de Guelph. A) Componentes do corpo do equipamento e interpretação das zonas formadas pelo fornecimento de água. B) Ponteira do permeâmetro aberta (adaptado de SOTO et al. 2009). 
FIQ é calculado a partir da relação entre o $1^{\circ}$ e o $3^{\circ}$ quartis $\left(Q_{1}\right.$ e $Q_{3}$, respectivamente)

$$
F I Q=Q 3-Q 1
$$

Onde FIQ representa a faixa interquartil, $Q_{3}$ é o valor do $3^{\circ}$ Quartil (75\%) e $Q_{1}$ é o valor do $1^{\circ}$ Quartil (25\%).

A análise geoestatística partiu da premissa de que a condutividade hidráulica na área de estudo é uma variável regionalizada. Isso significa que a distribuição dos valores segue duas fontes, uma aleatória e outra estrutural (LANDIM 2006). A aleatória corresponde ao conjunto de fatores não compreendidos no comportamento da variável. A componente estrutural é a ligação entre os pontos no espaço com base na gênese do fenômeno natural.

Esta etapa tem como fundamento o conceito de interpolação como uma previsão ou estimativa do valor de uma variável de estudo em um ponto não amostrado. A partir das amostras distribuídas aleatoriamente pela área do estudo, utilizou-se o software ArcGIS (ESRI 2011) para realizar a análise geoestatística.

O método selecionado para a interpolação foi o da krigagem, por apresentar um dos melhores resultados para variações em pequena escala da condutividade hidráulica do solo (EGGLESTON \& ROJSTACZER 1998). Inicialmente foi selecionada a krigagem ordinária, com tipo de transformação logarítmica, e sem remoção de tendência. A transformação logarítmica foi escolhida pois os dados de condutividades hidráulica saturada apresentam uma distribuição logarítmica, devido à sua variação exponencial em relação às propriedades do solo.

Na segunda etapa efetuou-se o modelamento matemático da krigagem, que gera um modelo de previsão que melhor se ajusta aos valores amostrados e previstos por iterações. Na terceira etapa, que envolve atributos de análise da krigagem, foram deixados os valores pré-definidos pelo programa. A partir da quarta etapa já se obteve os dados do mapa final e um gráfico de dispersão dos valores reais versus calculados.

\section{RESULTADOS E DISCUSSÕES}

Os resultados das determinações da $\mathrm{K}_{\text {sat, }}$, apresentados na tabela 1 , mostram que a condutividade hidráulica variou de $1,99 \mathrm{E}^{-6}$ até $6,02 \mathrm{E}^{-2}$ $\mathrm{cm} \mathrm{s}^{-1}$.

Na tabela 2 são apresentados os resultados da análise estatística exploratória. A análise dos valores medidos indica que a sua distribuição no histograma é assimétrica positiva, a partir da análise da curva de ajuste normal (Figura 4); nesse caso, a média dos valores não representa adequadamente o conjunto. A medida de tendência central mais indicada para uma distribuição assimétrica é a mediana.

TABELA 1 - Identificação dos 48 pontos amostrados, com localização no sistema de coordenadas UTM, Datum WGS84, zona 22S e valores de condutividade hidráulica saturada $\left(\mathrm{K}_{\mathrm{sat}}\right)$.

\begin{tabular}{|c|c|c|c|}
\hline Ponto & $E W(m)$ & $N S(m)$ & $K_{\text {sat }}\left(\mathrm{cm} \mathrm{s}^{-1}\right)$ \\
\hline 1 & 772179 & 7541259 & $3,40 \mathrm{E}-03$ \\
\hline 2 & 771568 & 7540131 & $9,12 \mathrm{E}-04$ \\
\hline 3 & 772716 & 7538621 & $3,33 \mathrm{E}-05$ \\
\hline 4 & 771948 & 7538659 & $3,32 \mathrm{E}-03$ \\
\hline 5 & 771981 & 7537742 & $8,23 \mathrm{E}-04$ \\
\hline 6 & 772363 & 7537035 & $9,53 \mathrm{E}-06$ \\
\hline 7 & 773256 & 7536507 & $6,85 \mathrm{E}-06$ \\
\hline 8 & 776373 & 7538218 & $3,89 \mathrm{E}-04$ \\
\hline 9 & 776727 & 7538525 & $1,67 \mathrm{E}-03$ \\
\hline 10 & 776213 & 7539286 & $2,01 \mathrm{E}-03$ \\
\hline 11 & 777444 & 7538685 & $1,60 \mathrm{E}-03$ \\
\hline 12 & 777156 & 7540733 & $1,32 \mathrm{E}-03$ \\
\hline 14 & 777389 & 7534217 & $2,95 \mathrm{E}-05$ \\
\hline 15 & 777013 & 7533413 & $6,39 \mathrm{E}-05$ \\
\hline 16 & 776084 & 7533162 & $6,50 \mathrm{E}-04$ \\
\hline 17 & 774489 & 7535917 & $2,96 \mathrm{E}-05$ \\
\hline 18 & 777388 & 7542143 & $5,34 \mathrm{E}-04$ \\
\hline 19 & 778145 & 7537584 & $6,02 \mathrm{E}-02$ \\
\hline 21 & 776106 & 7540219 & $5,29 \mathrm{E}-03$ \\
\hline 22 & 776805 & 7537750 & $1,44 \mathrm{E}-02$ \\
\hline 23 & 777430 & 7536890 & $1,33 \mathrm{E}-04$ \\
\hline 24 & 777562 & 7535961 & $7,86 \mathrm{E}-05$ \\
\hline 25 & 775126 & 7539148 & $1,94 \mathrm{E}-03$ \\
\hline 26 & 774121 & 7539694 & $1,45 \mathrm{E}-03$ \\
\hline 28 & 775914 & 7538619 & $2,06 \mathrm{E}-02$ \\
\hline 29 & 775520 & 7537676 & 1,99E-02 \\
\hline 30 & 774854 & 7535259 & $1,99 \mathrm{E}-06$ \\
\hline 31 & 775518 & 7534693 & $1,30 \mathrm{E}-03$ \\
\hline 34 & 775428 & 7541881 & $3,60 \mathrm{E}-03$ \\
\hline 35 & 776450 & 7542288 & 7,01E-04 \\
\hline 36 & 774427 & 7540686 & $1,68 \mathrm{E}-03$ \\
\hline 37 & 773156 & 7540465 & $1,33 \mathrm{E}-04$ \\
\hline 38 & 773485 & 7541218 & $5,89 \mathrm{E}-04$ \\
\hline 40 & 776439 & 7537207 & $3,42 \mathrm{E}-04$ \\
\hline 41 & 774669 & 7537274 & $1,01 \mathrm{E}-02$ \\
\hline 42 & 776465 & 7534958 & $1,41 \mathrm{E}-03$ \\
\hline 43 & 776220 & 7534109 & $1,19 \mathrm{E}-03$ \\
\hline 45 & 773898 & 7538432 & $2,90 \mathrm{E}-03$ \\
\hline 46 & 777663 & 7537647 & $6,06 \mathrm{E}-03$ \\
\hline 47 & 777158 & 7538624 & $6,36 \mathrm{E}-04$ \\
\hline 48 & 776723 & 7539578 & $3,19 \mathrm{E}-03$ \\
\hline 49 & 775035 & 7538303 & $9,60 \mathrm{E}-03$ \\
\hline 50 & 774371 & 7536903 & $1,58 \mathrm{E}-02$ \\
\hline 51 & 774788 & 7536457 & $6,59 \mathrm{E}-03$ \\
\hline 52 & 777030 & 7536449 & $6,12 \mathrm{E}-04$ \\
\hline 53 & 777901 & 7536281 & $3,28 \mathrm{E}-03$ \\
\hline 54 & 776079 & 7537202 & $1,01 \mathrm{E}-02$ \\
\hline 55 & 776119 & 7535795 & $1,69 \mathrm{E}-02$ \\
\hline
\end{tabular}


TABELA 2 - Dados estatísticos do conjunto amostral. Valores de condutividade hidráulica saturada em $\mathrm{cm} \mathrm{s}^{-1}$.

\begin{tabular}{ll}
\hline \multicolumn{1}{c}{ Estatistica } & Valor \\
\hline Número de amostras & 48 \\
Valor mínimo & $1,99 \mathrm{E}-06$ \\
Valor máximo & $6,02 \mathrm{E}-02$ \\
Média & $4,95 \mathrm{E}-03$ \\
Variância & 95,96 \\
Desvio padrão & $9,80 \mathrm{E}-03$ \\
$1^{\circ}$ Quartil (25\%) & $4,25 \mathrm{E}-04$ \\
Mediana & $1,43 \mathrm{E}-03$ \\
$3^{\circ}$ Quartil (75\%) & $4,87 \mathrm{E}-03$ \\
Curtose & 21,70 \\
\hline
\end{tabular}

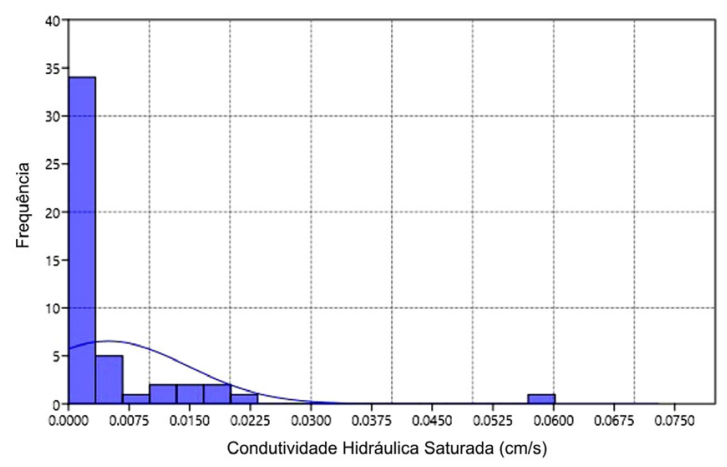

FIGURA 4 - Histograma dos valores de condutividade hidráulica saturada $\left(\mathrm{K}_{\text {sat }}\right)$ amostrados.

A curtose indica o grau de achatamento do histograma e o valor obtido $(21,70)$ indica que o diagrama é leptocúrtico, ou seja, apresenta uma distribuição concentrada dos valores da $\mathrm{K}_{\text {sat. }}$ Já a presença de valores de $\mathrm{K}_{\text {sat }}$ acima do $3^{\circ}$ quartil configura um potencial outlier a ser considerado na análise geoestatística, devendo, portanto, ser removido do conjunto amostral, uma vez que a krigagem é fortemente afetada pela presença de um outlier, pois o método considera sempre o valor da amostra. O mapa final é relativamente mais preciso sem os outliers.

Os outliers a serem considerados foram obtidos a partir da equação 2 e o valores superiores ao calculado, de $1,15 \mathrm{E}^{-2} \mathrm{~cm} \mathrm{~s}^{-1}$, foram encontrados apenas acima do $3^{\circ}$ Quartil (Figura 4). Dessa maneira, para o conjunto de amostras apresentado, seis apresentam valor de $\mathrm{K}_{\text {sat }}$ acima da referência $(19,22,28,29,50$ e 55$)$, as quais foram removidas para a análise geoestatística.

O modelo de semivariograma ajustado (Figura 5A) indica que o modelo stable é o que melhor se ajusta à distribuição espacial encontrada. Dentre os parâmetros de ajuste foi selecionada a distribuição isotrópica dos dados, em quatro setores de $45^{\circ}$. O ajuste do modelo apresenta um desvio (Figura $5 \mathrm{~B}$ ), com valores previstos geralmente maiores que os observados.

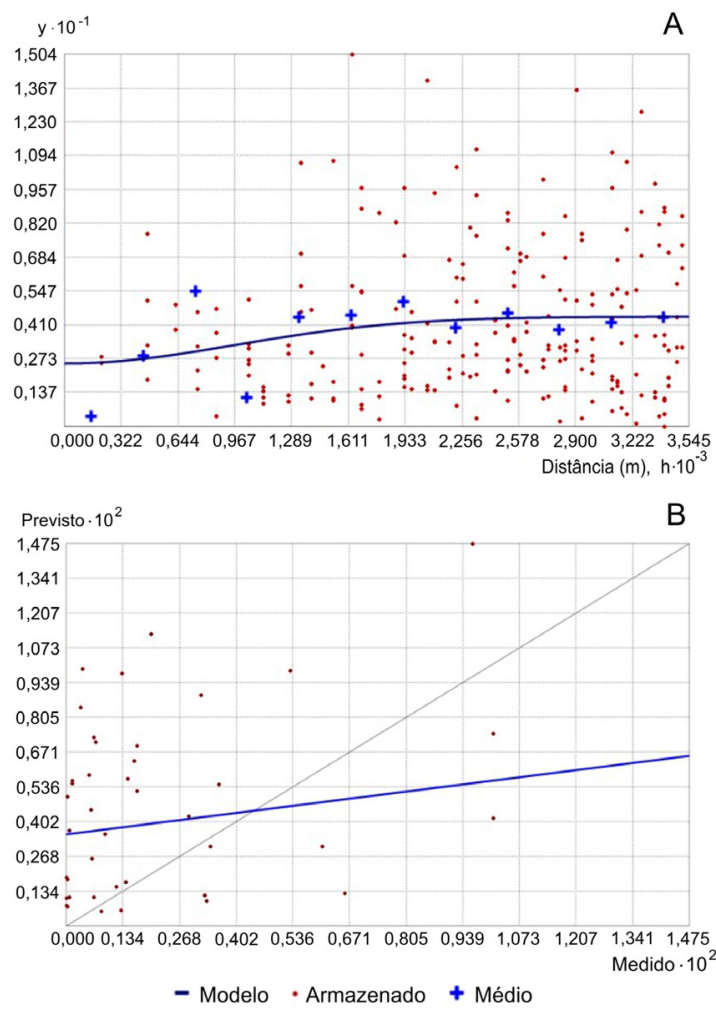

FIGURA 5 - Semivariograma modelado para as amostras de condutividade hidráulica saturada (A). Gráfico de dispersão dos valores previstos e medidos (B).

A análise da distribuição espacial da condutividade hidráulica saturada é apresentada na figura 6, mostrando claramente a sua associação com a compartimentação litológica. Nas partes mais baixas da bacia, caracterizadas por colinas suaves com desenvolvimento de drenagens de pequena ordem, há predominância de solos arenosos associados às formações Botucatu e Pirambóia. Nestas os valores de $\mathrm{K}_{\text {sat }}$ são da ordem de $1 \mathrm{E}^{-2}$ a $1 \mathrm{E}^{-3} \mathrm{~cm} \mathrm{~s}^{-1}$, portanto classificados como solos de alta permeabilidade (KUTILEK \& NIELSEN 1994). Nas porções mais elevadas da bacia, que correspondem ao reverso do relevo de cuestas, se associam os latossolos vermelhos decorrentes da alteração dos basaltos da Formação Serra Geral. Estes apresentam valores de $\mathrm{K}_{\text {sat }}$ muito menores que $1 \mathrm{E}^{-4} \mathrm{~cm} \mathrm{~s}^{-1}$, portanto classifi- 
cados como solos de baixa a muito baixa permeabilidade (KUTILEK \& NIELSEN 1994).

Os valores da $\mathrm{K}_{\text {sat }}$ medidos nos solos associados às unidades psamíticas (formações Botucatu e Pirambóia) apresentam uma distribuição inversa em relação à esperada. Por ter maior conteúdo em argila, os solos da Formação Pirambóia deveriam apresentar valores de $\mathrm{K}_{\text {sat }}$ inferiores aos da Formação Botucatu, entretanto observa-se o inverso. Esse fato pode ser explicado pela maior infiltração de argilas nos solos arenosos da Formação Botucatu devido a sua proximidade com inúmeros depósitos coluvionares associados às cuestas basálticas presentes na área.

Sob a perspectiva geológica, variações dentro de uma mesma unidade podem indicar diferentes teores de argila nos solos residuais. No caso da Formação Piramboia, descrita na literatura como constituída por arenitos com teores variáveis de argila (MILANI et al. 2007), as anomalias positivas podem indicar locais em que há teores muito altos de

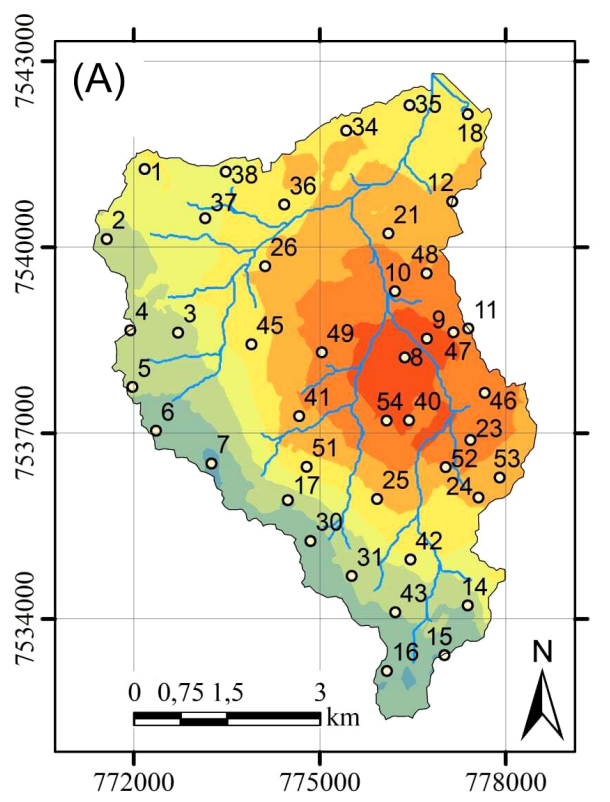

Legenda

Ponto de amostragem

Mapa de Previsão (Krigagem)

Condutividade Hidráulica Saturada $(\mathrm{cm} / \mathrm{s})$

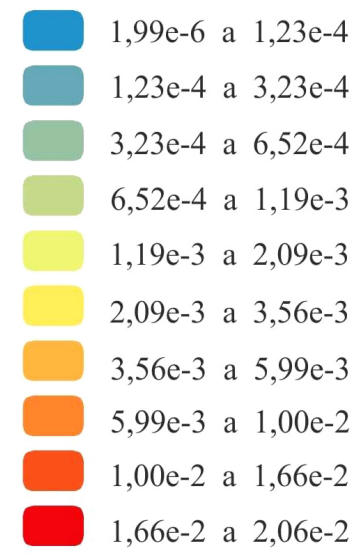

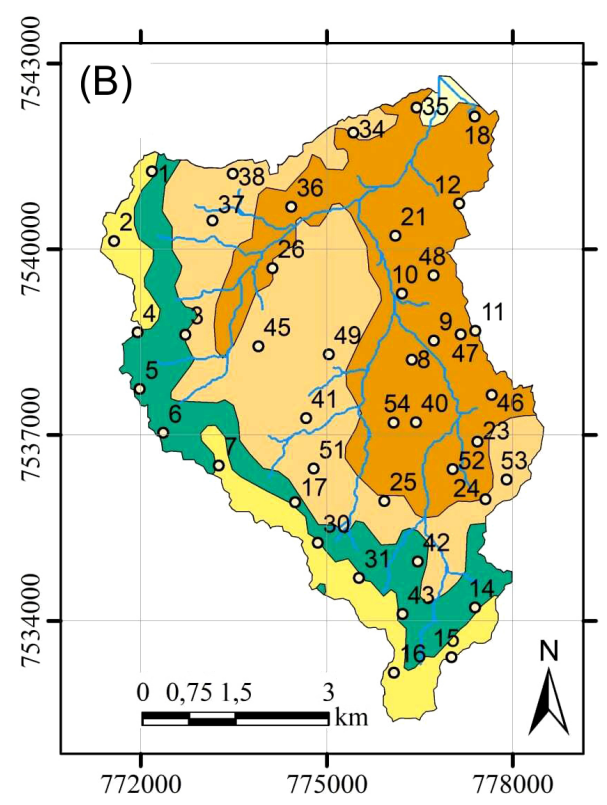

Unidades Litológicas

$\checkmark$ Depósitos aluvionares

3 Depósitos colúvio-eluvionares

C Formação Botucatu

$\sim$ Formação Piramboia

Formação Serra Geral

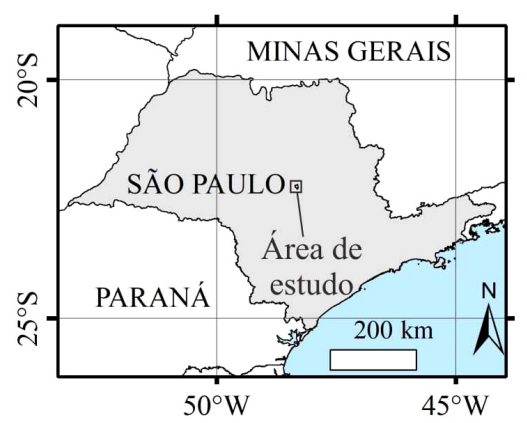

FIGURA 6 - (A) Mapa da variação espacial da condutividade hidráulica saturada pelo método geoestatístico de krigagem ordinária. (B) Mapa geológico da microbacia, com dados da base vetorial GeoSGB. 
areia, enquanto valores mais baixos estão associados às porções mais argilosas dessa unidade.

Os valores de $\mathrm{K}_{\text {sat }}$ dos solos argilosos estão de acordo com os dados encontrados na literatura, com valores mínimos atingindo a ordem de $1 \mathrm{E}^{-6}$ $\mathrm{cm} \mathrm{s}^{-1}$ (MESSING \& JARVIS 1993, GHOSH et al. 2019). Segundo MESSING \& JARVIS (1993), a sazonalidade climática é um fenômeno que afeta a condutividade hidráulica de solos argilosos predominantemente na parte mais superficial, por conta da interação solo-atmosfera. Na técnica executada neste trabalho os dados foram obtidos a uma profundidade de $30 \mathrm{~cm}$, portanto são menos sensíveis a possíveis influências desta interação. É possível inferir que há mínima contribuição da compactação ou criação de macroporos causada pelas oscilações da pluviosidade e temperatura.

No entanto, os valores de $\mathrm{K}_{\text {sat }}$ de solos argilosos podem ser discutidos com base em outros fatores físicos do mesmo, tais como tamanho de grãos, continuidade e orientação dos poros (KLEIN \& LIBARDI 2002). Práticas agrícolas podem alterar algumas dessas características, promovendo, por exemplo, a compactação do solo nas camadas superficiais. Outro fator que influencia a condutividade hidráulica é o conteúdo de matéria orgânica, que, de maneira geral, pode aumentar a condutividade hidráulica e/ou a retenção de água no solo (NEMES et al. 2005). Estes elementos podem causar mudanças diretas na zona não saturada do solo e são controladores do comportamento da taxa de infiltração em zona de recarga de aquíferos (MANZIONE et al. 2015).

Assim, diferentes usos da terra influenciam a condutividade hidráulica, mesmo que em solos semelhantes. Práticas mais intensivas levam à diminuição da condutividade hidráulica; assim esperam-se valores menores em áreas agrícolas e de pastagem do que em áreas naturais (ZIMMERMANN et al. 2006). Isto pode ser observado na distribuição dos valores de condutividade hidráulica na porção norte da bacia, onde predomina o uso do solo de pastagem e plantação de cana-de-açúcar, em uma zona de baixada.

De modo geral, o valor da média geométrica da $\mathrm{K}_{\mathrm{sat}}$ está de acordo com o esperado para solos afetados por atividades agrícolas (SOLDERA \& MANZIONE 2012). Os valores obtidos pelo ensaio com o Permeâmetro de Guelph foram próximos aos ensaios de condutividade calculados a partir de dados de monitoramento de poços, apresentando valor médio com mesma ordem de grandeza que dos trabalhos de SOLDERA \& MANZIONE (2012) e MANZIONE et al. (2015).
Na tabela 3 é apresentada a validação cruzada dos dados de condutividade hidráulica para os pontos considerados no modelo. Segundo YAMAMOTO \& LANDIM (2013), a validação cruzada não tem como objetivo provar que o modelo para semivariograma escolhido é o mais correto, e sim que o modelo não está completamente errado. Como indicado na Figura 5(B), os valores previstos tendem a ser maiores que os medidos, e este fenômeno foi ob-

TABELA 3 - Validação cruzada dos valores de condutividade hidráulica saturada em $\mathrm{cm} \mathrm{s}^{-1}$.

\begin{tabular}{|c|c|c|c|}
\hline Ponto & $K_{\text {sat }}\left(\mathrm{cm} \mathrm{s}^{-1}\right)$ medido & Previsto & Erro \\
\hline 1 & $3,40 \mathrm{E}-03$ & $1,29 \mathrm{E}-02$ & $9,47 \mathrm{E}-03$ \\
\hline 2 & $9,12 \mathrm{E}-04$ & $5,41 \mathrm{E}-03$ & $4,50 \mathrm{E}-03$ \\
\hline 3 & $3,33 \mathrm{E}-05$ & $3,15 \mathrm{E}-03$ & $3,12 \mathrm{E}-03$ \\
\hline 4 & $3,32 \mathrm{E}-03$ & $6,48 \mathrm{E}-03$ & $3,16 \mathrm{E}-03$ \\
\hline 5 & $8,23 \mathrm{E}-04$ & 4,33E-03 & $3,51 \mathrm{E}-03$ \\
\hline 6 & $9,53 \mathrm{E}-06$ & $9,59 \mathrm{E}-04$ & $9,50 \mathrm{E}-04$ \\
\hline 7 & $6,85 \mathrm{E}-06$ & $8,72 \mathrm{E}-04$ & $8,65 \mathrm{E}-04$ \\
\hline 8 & $3,89 \mathrm{E}-04$ & $9,44 \mathrm{E}-02$ & $9,40 \mathrm{E}-02$ \\
\hline 9 & $1,67 \mathrm{E}-03$ & 7,31E-02 & $7,15 \mathrm{E}-02$ \\
\hline 10 & $2,01 \mathrm{E}-03$ & 4,89E-02 & $4,68 \mathrm{E}-02$ \\
\hline 11 & $1,60 \mathrm{E}-03$ & $4,12 \mathrm{E}-02$ & $3,96 \mathrm{E}-02$ \\
\hline 12 & $1,32 \mathrm{E}-03$ & $2,09 \mathrm{E}-02$ & $1,96 \mathrm{E}-02$ \\
\hline 14 & $2,95 \mathrm{E}-05$ & $2,09 \mathrm{E}-03$ & $2,06 \mathrm{E}-03$ \\
\hline 15 & $6,39 \mathrm{E}-05$ & $1,61 \mathrm{E}-03$ & $1,55 \mathrm{E}-03$ \\
\hline 16 & $6,50 \mathrm{E}-04$ & $2,11 \mathrm{E}-03$ & $1,46 \mathrm{E}-03$ \\
\hline 17 & $2,96 \mathrm{E}-05$ & $2,25 \mathrm{E}-03$ & $2,22 \mathrm{E}-03$ \\
\hline 18 & $5,34 \mathrm{E}-04$ & $1,05 \mathrm{E}-02$ & $9,93 \mathrm{E}-03$ \\
\hline 21 & $5,29 \mathrm{E}-03$ & $2,94 \mathrm{E}-02$ & $2,41 \mathrm{E}-02$ \\
\hline 23 & $1,33 \mathrm{E}-04$ & $5,12 \mathrm{E}-02$ & $5,10 \mathrm{E}-02$ \\
\hline 24 & $7,86 \mathrm{E}-05$ & $2,92 \mathrm{E}-02$ & $2,92 \mathrm{E}-02$ \\
\hline 25 & $3,89 \mathrm{E}-03$ & $2,07 \mathrm{E}-02$ & $1,68 \mathrm{E}-02$ \\
\hline 26 & $1,45 \mathrm{E}-03$ & $1,86 \mathrm{E}-02$ & $1,72 \mathrm{E}-02$ \\
\hline 30 & $1,99 \mathrm{E}-06$ & $7,21 \mathrm{E}-04$ & $7,19 \mathrm{E}-04$ \\
\hline 31 & $1,30 \mathrm{E}-03$ & 4,82E-03 & $3,52 \mathrm{E}-03$ \\
\hline 34 & $3,60 \mathrm{E}-03$ & $2,01 \mathrm{E}-02$ & $1,65 \mathrm{E}-02$ \\
\hline 35 & $7,01 \mathrm{E}-04$ & $1,13 \mathrm{E}-02$ & $1,06 \mathrm{E}-02$ \\
\hline 36 & $1,68 \mathrm{E}-03$ & $1,53 \mathrm{E}-02$ & $1,36 \mathrm{E}-02$ \\
\hline 37 & $1,33 \mathrm{E}-04$ & $6,34 \mathrm{E}-03$ & $6,21 \mathrm{E}-03$ \\
\hline 38 & $5,89 \mathrm{E}-04$ & $8,60 \mathrm{E}-03$ & $8,01 \mathrm{E}-03$ \\
\hline 40 & $3,42 \mathrm{E}-04$ & $6,46 \mathrm{E}-02$ & $6,43 \mathrm{E}-02$ \\
\hline 41 & $1,01 \mathrm{E}-02$ & $3,24 \mathrm{E}-02$ & $2,23 \mathrm{E}-02$ \\
\hline 42 & $1,41 \mathrm{E}-03$ & $1,03 \mathrm{E}-02$ & $8,88 \mathrm{E}-03$ \\
\hline 43 & 1,19E-03 & $3,90 \mathrm{E}-03$ & 2,71E-03 \\
\hline 45 & $2,90 \mathrm{E}-03$ & $1,60 \mathrm{E}-02$ & $1,31 \mathrm{E}-02$ \\
\hline 46 & $6,06 \mathrm{E}-03$ & 4,39E-02 & $3,78 \mathrm{E}-02$ \\
\hline 47 & $6,36 \mathrm{E}-04$ & $5,98 \mathrm{E}-02$ & $5,91 \mathrm{E}-02$ \\
\hline 48 & $3,19 \mathrm{E}-03$ & $3,36 \mathrm{E}-02$ & $3,04 \mathrm{E}-02$ \\
\hline 49 & $9,60 \mathrm{E}-03$ & $5,09 \mathrm{E}-02$ & $4,13 \mathrm{E}-02$ \\
\hline 51 & $6,59 \mathrm{E}-03$ & $1,90 \mathrm{E}-02$ & $1,24 \mathrm{E}-02$ \\
\hline 52 & $6,12 \mathrm{E}-04$ & $3,03 \mathrm{E}-02$ & $2,97 \mathrm{E}-02$ \\
\hline 53 & $3,28 \mathrm{E}-03$ & $2,53 \mathrm{E}-02$ & $2,20 \mathrm{E}-02$ \\
\hline 54 & $1,01 \mathrm{E}-02$ & $5,63 \mathrm{E}-02$ & 4,62E-02 \\
\hline
\end{tabular}


servado em todos os 42 pontos da validação cruzada. Em histograma estes dados apresentam uma distribuição exponencial, caracterizada por formato assimétrico com a maior parcela de valores próximo ao valor mínimo $\left(7,19 \mathrm{E}^{-04}\right)$.

Para melhor visualizar a distribuição dos erros na área, foi confeccionado o mapa da figura 7. Ao comparar os resultados da validação cruzada com o mapa de erro, fica claro que houve uma suavização dos dados no processo de krigagem. As estimativas podem variar em até 2 ordens de grandeza, fenômeno observado na região centro-leste da bacia.

Em relação ao comportamento da $\mathrm{K}_{\text {sat }}$ na zona vadosa de solos argilosos (FALLEIROS et al. 1998, LIBARDI \& MELHO FILHO 2006), nenhum dos pontos amostrados nesses solos foi considerado outlier, e os mapas permitem interpretar que a variação da $\mathrm{K}_{\text {sat }}$ nesses casos foi a melhor prevista pelo método. Isto pode indicar que na escala de trabalho não houve variações significativas no teor de água de solo, que causariam mudanças drásticas na variabilidade espacial da $\mathrm{K}_{\text {sat. }}$.

Um fator que pode ter contribuído para a anomalia de valores na região dos pontos $8,9,11,47$ e adjacentes é o conteúdo de água no solo. Como é uma área topograficamente rebaixada em relação aos morros adjacentes, esta região é mais favorável ao acúmulo de água pelo escoamento em superfície e sub-superfície. O maior conteúdo em água pode ter favorecido um forte incremento nos valores de $\mathrm{K}_{\text {sat }}$ (LIBARDI \& MELO FILHO 2006). Este aumento ocorre em uma escala que foge à distribuição espacial calculada pelo modelo para os valores de $\mathrm{K}_{\text {sat, }}$ fator que pode ser responsável por aumentar o erro médio na região.

\section{CONCLUSÕES}

O estudo da variabilidade da condutividade hidráulica em uma microbacia hidrográfica é uma das etapas na análise e interpretação dos fatores controladores do fluxo de água e de balanço hídrico. Os resultados obtidos nesta pesquisa permitem apontar que a aplicação do método do Permeâmetro de Guelph na estimativa da condutividade hidráulica saturada apresenta resultados consistentes, pois estão associados aos diferentes tipos de solo que ocorrem na área.

Por se tratar de levantamento básico inicial associado a outros estudos relacionados a movimentação da água em área de recarga do SAG no

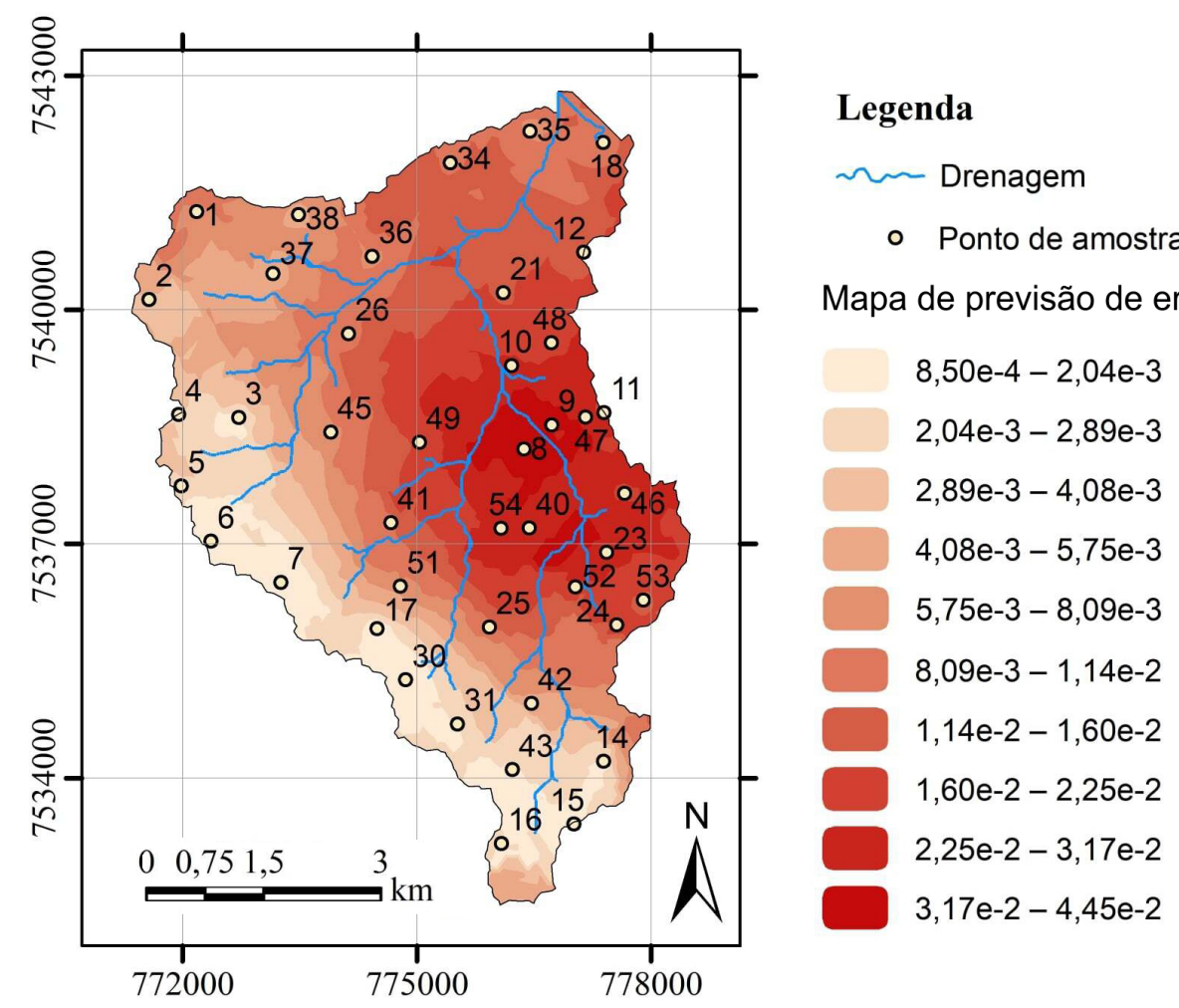

FIGURA 7 - Previsão de erro do modelo aplicado para a condutividade hidráulica saturada. 
estado de São Paulo, esse trabalho poderá auxiliar na tomada de decisões para a gestão de recursos hídricos, uma vez que é fundamental a manutenção do acesso à água pela população.

Além disso, a identificação de áreas com maiores ou menores valores de condutividade hidráulica saturada pode auxiliar na definição de áreas onde as águas subterrâneas estejam mais ou menos suscetíveis à contaminação antrópica, pois a condutividade hidráulica é o principal parâmetro para definir a velocidade de percolação da água em meio poroso. Essa informação é importante para descrever fluxos descendentes de água ou de contaminantes (recarga), bem como fluxos ascendentes, representados pela descarga das águas subterrâneas nos leitos das drenagens.

\section{AGRADECIMENTOS}

Os autores agradecem ao Prof. Dr. Chang Hung Kiang, do Laboratório de Estudo de Bacias (LEBAC - UNESP, campus Rio Claro) por disponibilizar o permeâmetro para a pesquisa. O primeiro autor gostaria de agradecer ao $\mathrm{CNPq}$ pela concessão de bolsa de iniciação científica (Projeto PIBIC $n^{\circ}$ 800571/2016-9). Os autores também agradecem à FAPESP pela concessão de recursos para a realização desse estudo (Projeto FAPESP 2015/15749-2).

\section{REFERÊNCIAS BIBLIOGRÁFICAS}

ALMEIDA, F.F.M. 1964. Fundamentos geológicos do relevo paulista. São Paulo: Instituto Geográfico e Geológico, 96 p. (Boletim, 41).

BACCHI, O.O.S.; CORRENTE, J.E.; REICHARDT, K. 1991. Análise comparativa de dois métodos simplificados de determinação da condutividade hidráulica de solos. Revista Brasileira de Ciência do Solo, 15(3): 249252.

BATISTA, L.V. 2015. Hidrogeoquímica e qualidade das águas superficiais na Bacia do Alto Jacaré-Pepira (SP). Instituto de Geociências e Ciências Exatas, Universidade Estadual Paulista, Rio Claro, Dissertação de Mestrado, $106 \mathrm{p}$.

BATISTA, L.V.; GASTMANS, D. 2015. Hidrogeoquímica e qualidade das águas superficiais na bacia do Alto JacaréPepira (SP), Brasil. Pesquisas em
Geociências, 42(3), 297-311. https://doi. org/10.22456/1807-9806.78186

BATISTA, L.V.; GASTMANS, D.; SÁNCHEZMURILLO, R.; FARINHA, B.S.; DOS SANTOS, S.M.R.; KIANG, C.H. 2018. Groundwater and surface water connectivity within the recharge area of Guarani aquifer system during El Niño 2014-2016. Hydrological Processes, 32(16): 2483-2495. https://doi.org/10.1002/hyp.13211

BUCKINGHAM, E. 1907. Studies on the movement of soil moisture. US Department of Agriculture, Bureau of Soils Bulletin, 38: $1-61$.

BUENO, C.R.P.; MENDES, I.A. 1999. Análise geomorfológica da bacia do JacaréPepira (SP). Revista GEOUSP, 6: 61-77. https://doi.org/10.11606/issn.2179-0892. geousp.1999.123365

CAMPOS, J.E.G. 2004. Hidrogeologia do Distrito Federal: bases para a gestão dos recursos hídricos subterrâneos. Revista Brasileira de Geociências, 34(1): 41-48. http://www.dx.doi.org/10.25249/03757536.20043414148

CHENG, L.; LIU, W.; LI, Z.; CHEN, J. 2014. Study of soil water movement and groundwater recharge for the loess tableland using environment tracers. American Society of Agricultural Biology Engineering, 57: 23 30 .

CORDEIRO NETTO, O.M.; TUCCI, C.E.M. 2003. Os desafios em ciência, tecnologia \& inovação: resultados alcançados com o fundo setorial de recursos hídricos. Ciência e Cultura, 55(4): 44-46. Disponível em http://cienciaecultura.bvs.br/scielo. php? script $=$ sci_arttext\&pid=S 0009 $67252003000400024 \& \operatorname{lng}=\mathrm{en} \& \mathrm{nrm}=\mathrm{iso}$. Acessado em 13 ago. 2017.

CRH - CONSELHO ESTADUAL DE RECURSOS HÍDRICOS. 2006. Plano Estadual de Recursos Hídricos: 2004/2007: Resumo. CRH/DAEE, São Paulo (Relatório técnico do Conselho Estadual de Recursos Hídricos). Disponível em http://www.daee.sp.gov.br/ acervoepesquisa/perh2204_2207/perh01.pdf. Acessado em 04 dez. 2017. 
DA SILVA, E.R. 1998. O curso da água na história: simbologia, moralidade e a gestão de recursos hídricos. Escola Nacional de Saúde Pública Sérgio Arouca, Fundação Oswaldo Cruz, Rio de Janeiro, Tese de Doutorado em Saúde Pública, 201 p.

DARCY, H. 1856. Les Fontaines Publiques de la Ville de Dijon. Victor Dalmont, Paris, 658 p.

EGGLESTON, J.; ROJSTACZER, S. 1998. Identification of large-scale hydraulic conductivity trends and the influence of trends on contaminant transport. Water Resources Research, 34(9): 2155-2168. https://doi.org/10.1029/98WR01475

ESRI. 2011. ArcGIS Desktop: Release 10. Redlands, CA: Environmental Systems Research Institute.

FALLEIROS, M.C.; PORTEZAN, O.; OLIVEIRA, J.C.M.; BACCHI, O.O.S.; REICHARDT, K. 1998. Spatial and temporal variability of soil hydraulic conductivity in relation to soil water redistribution, using an exponential model. Soil and Tillage Research, 45(3): 279-285. https://doi.org/10.1016/S09333630(97)00021-4

FETTER, C.W. 2000. Applied hydrogeology. Pearson, Harlow, $4^{\text {th }}$ edition, $624 \mathrm{p}$.

FIORI, J.; CAMPOS, J.E.G.; ALMEIDA, L. 2010. Variabilidade da condutividade hidráulica das principais classes de solos do Estado de Goiás. Geociências, 29(2): 229-235.

FREEZE, R.A.; CHERRY, J.A. 1979. Groundwater. Prentice-Hall, Englewood Cliffs, 604 p.

GASTMANS, D., CHANG, H.K., HUTCHEON, I. 2010. Stable isotopes $\left({ }^{2} \mathrm{H},{ }^{18} \mathrm{O}\right.$ and $\left.{ }^{13} \mathrm{C}\right)$ in groundwaters from the northwestern portion of the Guarani Aquifer System (Brazil). Hydrogeology Journal, 18: 1497-1513. https://doi.org/10.1007/s10040-010-0612-2

GESICKI, A.L.D. 2007. Evolução diagenética das formações Pirambóia e Botucatu (Sistema Aquífero Guarani) no Estado de São Paulo. Instituto de Geociências, Universidade de São Paulo, São Paulo, Tese de Doutorado, $165 \mathrm{p}$.
GHOSH, B.; PEKKAT, S.; YAMSANI, S. 2019. Evaluation of infiltrometers and permeameters for measuring hydraulic conductivity. Advances in Civil Engineering Materials, 8(1): 307-321. https://doi. org/10.1520/ACEM20180056

GONÇALVES, A.D.M.; LIBARDI, P.L. 2013. Análise da determinação da condutividade hidráulica do solo pelo Método do Perfil Instantâneo. Revista Brasileira de Ciências do Solo, 37(5): 1174-1184. http://dx.doi. org/10.1590/S0100-06832013000500007

HAMMER, Ø.; HARPER, D.A.T.; RYAN, P.D. 2001. Paleontological statistics software: package for education and data analysis. Palaeontologia Electronica. Disponível em http://palaeo-electronica.org/2001_1/past/ issue1_01.htm. Acessado em 10 set. 2018.

HILLEL, D. 1971. Soil water: Physical principles and processes. Academic Press, New York, $288 \mathrm{p}$.

IPT - INSTITUTO DE PESQUISAS TECNOLÓGICAS DO ESTADO DE SÃO PAULO. 2015. Relatório de Situação dos Recursos Hídricos 2015. Comitê da Bacia Hidrográfica do Tietê-Jacaré, Araraquara, 130 p.

KANWAR, R.S.; RIZVI, H.A.; AHMED, M.; HORTON, R.; MARLEY, S.J. 1990. Measurement of field-saturated hydraulic conductivity by using Guelph and velocity permeameters. Transactions of the ASAE, 32(6): 1885-1890. https://doi. org/10.13031/2013.31239

KLEIN, V.A.; LIBARDI, P.L. 2002. Condutividade hidráulica de um Latossolo Roxo, não saturado, sob diferentes sistemas de uso e manejo. Ciência Rural, 32: 945-953. https:// doi.org/10.1590/s0103-84782002000600006.

KRESIC, N. 2007. Hydrogeology and groundwater modeling. CRC Press/Taylor \& Francis, Boca Raton, 828 p.

KUTILEK, M.; NIELSEN, D.R. 1994. Soil hydrology: textbook for students of soil science, agriculture, forestry, geoecology, hydrology, geomorphology and other related disciplines. Catena Publishers, CremlingenDestedt, $370 \mathrm{p}$. 
LANDIM, P.M.B. 2006. Introdução aos métodos de estimação espacial para confecção de mapas. IGCE/UNESP, Rio Claro, (Texto Didático 02 do Laboratório de Geomatemática). Disponível em http://www.sorocaba.unesp. br/Home/Graduacao/EngenhariaAmbiental/ robertowlourenco/dicas-surfer-01.pdf. Acessado em 10 set. 2018.

LIBARDI, P.L.; MELO FILHO, J.F. 2006. Análise exploratória e variabilidade dos parâmetros da equação da condutividade hidráulica, em um experimento de perfil instantâneo. Revista Brasileira de Ciências do Solo, 30(2): 197-206. http://dx.doi.org/10.1590/ S0100-06832006000200001

MANZIONE, R.L.; SOLDERA, B.C.; PAES, C.O.; WENDLAND, E.E. 2015. Analyses of water table depths variations in an outcrop area of the Guarani Aquifer System in Brotas/ SP-Brazil. Irriga, Edição Especial, 20 anos Irriga +50 anos FCA: 186-197. https://doi. org/10.15809/irriga.2015v1n1p186

MARENGO, J.A. 2008. Água e mudanças climáticas. Estudos Avançados, 22(63): 83-96. http://dx.doi.org/10.1590/S010340142008000200006

MESQUITA, M.D.G.B.D.; MORAES, S.O. 2004. A dependência entre a condutividade hidráulica saturada e atributos físicos do solo. Ciência Rural, 34(3): 963-969. http://dx.doi. org/10.1590/S0103-84782004000300052.

MESSING, I.; JARVIS, N.J. 1993. Temporal variation in the hydraulic conductivity of a tilled clay soil as measured by tension infiltrometers. Journal of Soil Science, 44(1): 11-24. http:// dx.doi.org/10.1111/j.1365-2389.1993. tb00430.x

MILANI, E.J.; FRANÇA, A.B.; SCHNEIDER, R.L. 2007 Bacia do Paraná. Boletim de Geociências da Petrobras, 15(2): 265-287.

MOHANTY, B.P.; KANWAR, R.S.; EVERTS, C.J. 1994. Comparison of saturated hydraulic conductivity measurement methods for a glacial-till soil. Soil Science Society of America Journal, 58(3): 672-677. http://dx.doi.org/10.2136/ sssaj1994.03615995005800030006x
MONTANHEIRO, F.; TERAMOTO, E.H.; ENGELBRECH, B.Z.; KIANG, C.H. 2016. Testes de bombeamento como requisitos para elaboração de modelos hidrogeológicos conceituais: estudo de caso no Aquífero Serra Geral. In: ABAS, CONGRESSO BRASILEIRO DE ÁGUAS SUBTERRÂNEAS, 19, Campinas, Anais. 19 p. https://doi.org/10.14295/ras.v0i0.28845

NEMES, A.; RAWLS, W.J.; PACHEPSKY, Y.A. 2005. Influence of organic matter on the estimation of saturated hydraulic conductivity. Soil Science Society of America Journal Abstract - Soil Physics, 69(4): 1330-1337. https://doi.org/10.2136/ sssaj2004.0055

NIST/SEMATECH - NATIONAL INSTITUTE OF STANDARDS AND TECHNOLOGY. 2003. e-Handbook of Statistical Methods. Disponível em https://www.itl.nist.gov/ div898/handbook/. Acessado em 01 set. 2018 .

OEA - ORGANIZAÇÃO DOS ESTADOS AMERICANOS. 2009. Aquifero Guarani: programa estratégico de ações [Guarani Aquifer: strategic program of actions]. OEA, Washington, DC, 424 p.

PEEL, M.C.; FINLAYSON, B.L.; MCMAHON, T.A. 2007. Updated world map of the Köppen-Geiger climate classification. Hydrology and Earth System Sciences, 11(5): 1633-1644. https://doi.org/10.5194/hess-111633-2007

RABELO, J.L. 2006. Estudo da recarga do Aqüifero Guarani no sistema JacaréTietê. Escola de Engenharia de São Carlos, Universidade de São Paulo, São Carlos, Tese de Doutorado, $200 \mathrm{p}$.

REYNOLDS, W.D.; ELRICK, D.E. 1985. In situ measurement of field-saturated hydraulic conductivity, sorptivity, and the $\alpha$-parameter using the Guelph permeameter. Soil Science, 140(4): 292-302.

REYNOLDS, W.D.; ELRICK, D.E. 1987. A laboratory and numerical assessment of the Guelph permeameter method. Soil Science, 144(4): 282-299. 
REYNOLDS, W.D.; ELRICK, D.E.; TOPP, G.C. 1983. A reexamination of the constant head well permeameter method for measuring saturated hydraulic conductivity above the water table1. Soil Science, 136(4): 250268. https://doi.org/10.1097/00010694198310000-00008

RICHARDS, L.A. 1931. Capillary conduction of liquids through porous medium. Physics, 1(5): 381-333. https://doi.org/10.1063/1.1745010

ROSSI, M. 2017. Mapa Pedológico do Estado de São Paulo: revisado e ampliado. Instituto Florestal, São Paulo, v. 1, 118 p.

SALVERDA, A.P.; DANE, J.H. 1993. An examination of the Guelph permeameter for measuring the soil's hydraulic properties. Geoderma, 57(4): 405-421. https://doi. org/10.1016/0016-7061(93)90052-M

SILVA, C.L.; KATO, E. 1997. Efeito do selamento superficial na condutividade hidráulica saturada da superfície de um solo sob cerrado. Pesquisa Agropecuária Brasileira, 32(2): 213-220.

SOIL MOISTURE EQUIPMENT CORPORATION. 2012a. Guelph Permeameter K-sat Calculator. Disponível em https://www.soilmoisture. com/Calculators/Guelph-Permeameter-KsatCalculator-ver-3-1.xls. Acessado em 4 dez. 2017.

SOIL MOISTURE EQUIPMENT CORPORATION. 2012b. Model 2800K1 Guelph Permeameter Operating Instructions. Disponível em: https:// www.soilmoisture.com/pdfs/Resource Instructions_0898-2800_2800K $1 \% 20$ Guelph\%20Permeameter\%20.pdf. Acessado em 04 dez. 2017.

SOLDERA, B.C.; MANZIONE, R.L. 2012. Modelagem de níveis freáticos no Sistema Aquífero Bauru como ferramenta na gestão de recursos hídricos subterrâneos. Ciência Geográfica, 16(1): 54-61.

SOTO, M.A.; VILAR, O.M. 1999. Estudio de la conductividad hidráulica en suelos no saturados. In: ABMS/ISSMGE, PANAMERICAN CONFERENCE ON SOIL MECHANICS AND GEOTECHNICAL
ENGINEERING, 11, Foz do Iguaçu, Proceedings, 921-928.

SOTO, M.A.; CHANG, K.H.; VILAR, O.M. 2009. Análise do método do Permeâmetro de Guelph na determinação da condutividade hidráulica saturada. Águas Subterrâneas, 23(1): 137-152. https://doi.org/10.14295/ras. v23i1.17004

SSRH/CRHI - SECRETARIA DE SANEAMENTO E RECURSOS HIIDRICOS / COORDENADORIA DE RECURSOS HIIDRICOS. 2011. Relatório de Situação dos Recursos Hídricos do Estado de São Paulo: Ano Base 2009. SSRH/CRHi, São Paulo (Relatório Técnico).

TUCCI, C.E.M. 2007. Hidrologia: Ciência e Aplicação. Editora da UFRGS/ABRH, Porto Alegre, $943 \mathrm{p}$.

VAN GENUCHTEN, M.T. 1980. A closedform equation for predicting the hydraulic conductivity of unsaturated soils 1. Soil Science Society of America Journal, 44(5): 892-898. http://dx.doi.org/10.2136/ sssaj1980.03615995004400050002x

WATSON, K.K. 1966. An instantaneous profile method for determining the hydraulic conductivity of unsaturated porous materials. Water Resources Research, 2(4): 709-715. https://doi.org/10.1029/WR002i004p00709

YAMAMOTO, J.K.; LANDIM, P.M.B. 2013. Geoestatística: conceitos e aplicações. Oficina de Textos, São Paulo, 215 p.

ZHANG, Y.; SCHAAP, M.G. 2019. Estimation of saturated hydraulic conductivity with pedotransfer functions: A review. Journal of Hydrology, 575: 1011-1030. https://doi. org/10.1016/j.jhydrol.2019.05.058

ZIMMERMANN, B.; ELSENBEER, H.; DE MORAES, J.M. 2006. The influence of landuse changes on soil hydraulic properties: Implications for runoff generation. Forest Ecology and Management, 222: 29-38. https://doi.org/10.1016/j.foreco.2005.10.070 
Endereço dos autores:

Rodrigo Esteves Rocha, Didier Gastmans, Marcelo Donadelli Sacchi, Marcelo Dias de Oliveira Universidade Estadual Paulista "Júlio de Mesquita Filho" (UNESP), Centro de Estudos Ambientais (CEA), Av. 24A, 1515, Bela Vista, CEP: 13.506-900, Rio Claro, SP, Brasil. E-mails: rodestroc@gmail. com; didier.gastmans@unesp.br; link.mdsacchi@gmail.com; dias_oliveira@msn.com

Artigo submetido em 21 de julho de 2019, aceito em 31 de agosto de 2019. 